\title{
How Residential Schools led to Intergenerational Trauma in the Canadian Indigenous Population to Influence Parenting Styles and Family Structures Over Generations
}

\author{
Katie Cowan
}

\begin{abstract}
This paper intends to address current trauma among the Indigenous Canadian population due to the assimilationist goals of residential schools that influence parenting styles and the family structure. Other areas covered in this paper include parenting issues that the Indigenous community encounters every day. Additionally, social problems are examined in terms of intergenerational trauma and discussed further in terms of their influence and effect on the family structure of Indigenous communities in Canada. For example, education, health inequalities, and intimate partner violence are discussed. These issues are interrelated because of the detrimental and marginalized effect that residential schools have on survivors and generations to follow. Possible solutions to terminating family issues in the Indigenous community are by implementing specific methods that reflect the Indigenous way of life.
\end{abstract}

Katie Cowan is a student at MacEwan University in Edmonton, Alberta studying Sociology with a specialization in Family, Youth, and Diversity. She wants to use her background in Sociology to obtain a Psychology degree later on. Her dream job is working as a registered Psychologist, providing counselling to individuals with mental health issues. She would also like to work as an advocate for children with ADHD by utilizing the appropriate testing methods to correctly and efficiently diagnose struggling children. 


\section{Introduction}

The treatment of the Indigenous population in Canada throughout history has led to significant issues in the family structure and the Indigenous community as a whole. The deterioration of Indigenous families is due to cultural assimilationist institutions of the Canadian Federal Government, more specifically, the introduction of residential schools. The assimilationist goal of residential schools left survivors and future generations struggling to deal with the negative implications and trauma of stripping Indigenous children from their culture and languages. Addressing that many Indigenous children, although not all, were taken out of their homes at the time of residential school use in Canada is essential. Therefore, not all Indigenous experiences are the same, and their experiences cannot be generalized (Hoffart \& Jones, 2018, p. 28). To fully understand the concepts argued in this paper, it is important to define two specific terms that will remain consistent throughout the paper. One term that must be defined is Indigenous. Indigenous refers to the "First Peoples of Turtle Island, also known as Canada, which includes First Nations, Inuit, and Metis" (McIvor, Napoleon, \& Dickie, 2009, p. 7). Another term that needs to be defined is before continuing is intergenerational trauma. Hoffart and Jones (2018) defined intergenerational trauma as "the effect of a previous unresolved trauma passed on to subsequent generations of an individual's family, community, and culture" (p. 27).

Many characteristics of intergenerational trauma are directly related to the treatment of Indigenous children in residential schools. For example, residential schools consequently left Indigenous students without their Indigenous culture, traumatized, unable to cope, unable to form relationships, among many damaging social outcomes for the Indigenous population in Canada. In this paper, I will analyze the harmful impact that residential schools have on future generations of the Indigenous population. I will also discuss that the Indigenous community in Canada faces copious social problems that have not been resolved, therefore having detrimental effects on parenting and the Indigenous family structure as a whole.

\section{Literature Review}

Despite the adverse effects on Indigenous survivors of residential schools in Canada, the majority of research shows that intergenerational trauma resonates in further Indigenous generations, not just those who survived the residential school system. We see evidence showing that intergenerational trauma is a crucial determinant of social problems such as low socioeconomic status (Bombay et al., 2014; Hoffart \& Jones, 2018), health inequalities (Bombay et al., 2014; Hoffart \& Jones, 2018; Menzies, 2008; Niccols et al., 2010; Roy, 2014), high rates of intimate partner violence (Hoffart \& Jones, 2018), and substance and/or alcohol abuse (Hoffart \& Jones, 2018; Niccols et al., 2010), as well as various others. Much of the research done surrounding Indigenous intergenerational trauma addresses how experiences of survivors at residential schools influenced their children and further generations. The trauma endured by Indigenous survivors of residential schools has been passed down to further generations, reflected by social problems, leading to additional issues within the family structure.

Because the Indigenous population is harmfully affected by previous assimilationist institutions that have been passed on to future generations, many people are left dependent on 
mainstream social institutions, which may not cater to their individual needs (Menzies, 2008, p. 43). As Bombay et al. (2014) identified, in order to adequately address intergenerational trauma, we need to understand that "history provides a context for understanding individuals' present circumstances and it is an essential part of the healing process" (p. 333). By this, the statement generally means that we can understand the ways that the historical treatment of Indigenous Canadians affects survivors and later generations. The conception that healing may occur once addressing history appropriately by the Indigenous community, the Canadian Federal Government, and Canadian's as a whole. In addition to addressing the issue of intergenerational trauma, action must be taken by those working with the Indigenous community and the Canadian government.

\section{Residential Schools and Indigenous Canadians}

During the first treaty negotiation in 1807 , Indigenous leaders conveyed to government officials the necessity for the education of their people and the government responded by placing Indigenous peoples on reserves (Miller, as cited in Hoffart \& Jones, 2018, p. 26). The Canadian Federal Government later established the residential school system in 1883 due to the unsuccessful task, which was culturally assimilating the Indigenous community by placing them on reserves (Hoffart \& Jones, 2018, p. 26). According to Bombay et al. (2014), nineteenth-century Canada was, "marked by government policies to assimilate [Indigenous] peoples based on the assumption that [Europeans] were inherently superior to the [Indigenous] they considered to be savage and uncivilized" (p. 322). Barkan (as cited in Bombay et al., 2014) estimated that a staggering "150,000 Indigenous children were forcibly placed in residential schools between 1883 and 1996" (p. 26). All residential schools were operated in conjunction with religious orders and officials from Catholic, Anglican, and other churches that also worked with Indian agents and the federal police or the RCMP (Hoffart \& Jones, 2018, p. 27). The government took a large number of Indigenous children from their homes: "By 1930, roughly 75\% of all [Indigenous] children aged 7 to 15 attended residential schools" (Fournier \& Crey, as cited in Bombay et al., 2014, p. 322). According to Amrita Roy in 2014, children placed in residential schools were, "seized by force from their families and communities, mistreated, overworked, denied basic needs like food, water, and appropriate medical care, and both witnessed and personally experienced brutal physical, sexual and psychological abuse at the hands of school staff" (p. 213). Teaching Indigenous children that rejecting their family, ancestors, Indigenous culture and spiritual traditions as a whole would lead them to a more 'civilized' life later on (Roy, 2014, p. 213). According to Roy (2014), the assimilationist goal of residential schools left survivors, "lacking a sense of identity, lacking basic life skills, and highly traumatized from the chronic mistreatment and abuse they had endured" (p. 213). Gagne notes (cited in Menzies, 2008) that generations beyond attendees feel the effect of the residential school experience. The children of residential school students became victims of abuse as their parents became abusers because of the experiences faced at the schools (Menzies, 2008, p. 42). The treatment that Indigenous children received in residential schools led to severe social issues in terms of historical trauma, which transmits to later generations because of the inability to address and cope with previous traumas in Indigenous populations. 


\section{Intergenerational Trauma as a Result of Canadian Residential Schools}

Over the long periods that Indigenous children were taken from their homes to live in residential schools, Indigenous family values, knowledge about parenting, and community behaviour transmission were weakened between generations (Menzies, 2008, p. 42). The treatment of Indigenous children in residential schools led to an intergeneration cycle of violence, addiction, self-harm, and trauma (Roy, 2014, p. 213). Roy (2014) defines the symptoms of intergenerational trauma as the "maladaptive social and behavioural patterns ... created in response to the trauma experience, absorbed into the culture and transmitted as learned behaviour from generation to generation" (p. 213). Bombay et al. (2014) believed that historical trauma highlights that the "accumulation of collective stressors and trauma that began in the past may contribute to increased risk for negative health and social outcomes among contemporary [Indigenous] peoples" (p. 321). Those victimized by residential schools often remained silent, shielding their children from their past, hindering personal growth (Morrissette, 1994, p. 387). Consequently, children remain unaware of the hindering effects that residential schools had on their parents, which later affects them and their children (Morrissette, 1994, p. 387). Survivors of the harsh conditions of residential schools also possessed trust issues and intimacy confusion; therefore, they could not form meaningful relationships and isolation ensued (Roy, 2014, p. 213). The sense of isolation influences survivors and their family's preparedness for marriage, family life, and parenting (Roy, 2014 , p. 214). The children of residential school survivors became victims of abuse because of the experiences of their parents (Menzies, 2008, p. 42). The trauma that was experienced by those who attended residential schools has been described as a 'de-feathering process' stripping Aboriginal peoples of their knowledge, spirituality, physical and emotional well-being, and, most sadly, has led to the loss of community (Quinn, 2007, p. 73). Children of survivors of the traumatic environment of residential schools often adopted damaging coping mechanisms: "substance abuse, self-harm, criminal activity, and domestic violence against partners and children" (Roy, 2014, p. 214). In sum, the legacy of traumatized Indigenous individuals unable to function in mainstream society arose because of the residential school system, which led to the severing of the family structure (Menzies, 2008, p. 43). Therefore, intergenerational trauma in the Indigenous population reflects numerous social problems that have resonated in society for numerous years, having negative consequences for Indigenous families.

\section{Social Problems Experienced by Generations of Indigenous Canadians}

The intergenerational effect on Indigenous individuals in Canada stems from residential schools leading to disproportionate views of the Indigenous population as a whole. Often, Indigenous individuals are stigmatized based on societal perceptions of the Indigenous community as a whole. Societal perceptions and stereotypes of the Indigenous community often reflect specific social issues that Indigenous Canadians face. More common than not, there is an ignorance of the historical effects of residential schools, which are detrimental to survivors and their families. The social issues that are discussed in this section of the paper are interrelated and as a result, influence the Indigenous family structure. Niccols (2010) discussed individual Indigenous well-being as "inter-reliant with the well-being of the collective and its relation to self-identity" (p. 326). As a 
whole, the Indigenous population in Canada is reported to be near the bottom of socioeconomic well-being measurements, referring to employment, housing, education, and per capita incomes (Aguiar \& Halseth, as cited in Hoffart \& Jones, 2018, p. 28). It is significant to be aware that "approximately one quarter of [Indigenous] people move between First Nations reserves and urban areas, and their transient lifestyle can be a barrier to accessing employment, housing, and education" (Aboriginal Affairs and Northern Development Canada, as cited in Hoffart and Jones, 2018, p. 28). Using Niccol's (2010) definition of individual well-being, it is no surprise that the Indigenous population faces many social issues. The collective well-being of Indigenous Canada is significantly affected by the lack of self-identity originating from residential schools and Indigenous marginalization. With the Indigenous population recording near the lowest levels of socioeconomic well-being, beliefs may replicate in Canadian society that the Indigenous population cannot achieve higher standards due to negative consequences of residential schools on survivors, their families, and the whole Indigenous population in Canada. Entrenched beliefs about the Indigenous population in Canada based on social inequalities may attach senses of stigma to individuals, which is detrimental to the family structure.

\section{Education}

Education level is often used to determine later success in an individual's life and acts to determine the quality of life. In terms of Indigenous education, the Indigenous youth who had a parent attending residential schools were more likely to struggle at school in comparison to those who did not have a parent attending residential schools (Bombay et al., 2014, p. 324). Struggling at school could be explained by the idea of stress proliferation, which is exposing children to parental stress influences children "indirectly through social disadvantages and directly by altering parenting behaviours" (Bombay et al., 2014, p. 325). Alterations of parenting often by survivors leave their children suffering because of the abusive coping mechanism, which will be discussed later. Although Europeans believed the residential school system was beneficial for Indigenous students in attaining a "good" education by diminishing their Indigenous culture, many children ran away from the cruel discipline (Morrissette, 1994, p. 383). Additionally, residential school instructors were inadequate, to say the least (Morrissette, 1994, p. 383). The insufficient education level that residential school attendees received partially led to a lower income, therefore school success was lowered for their children and generations to follow (Bombay et al., 2014, p. 325). Consequently, it is no surprise that the Indigenous population of Canada continue to struggle with their education, occupation, and well-being due to the loss of traditional learning practices.

\section{Health Inequalities}

Health inequalities are examined to understand the interrelated nature of social problems due to the goals of residential schools that affect later generations of the Indigenous population. According to Mitchell and Maracle (2005), the "compounding trauma of cultural devaluation and loss and social ills is therefore important to assess in attempting to understand the current health crisis within [Indigenous] populations" (p. 16). Additionally, the health status of Indigenous Canadians cannot be related to economic status or to individual choices and lifestyles, which is a 
prevailing and limiting ideology (Mitchell \& Maracle, 2005, p. 15). Therefore, it is crucial to address the ways that the traumatic nature of residential schools negatively affects Indigenous individuals and the whole Indigenous community. Several scholars have identified health issues among the Indigenous population involve, but not are strictly: mental health (Bombay et al., 2014; Hoffart \& Jones, 2018; Menzies, 2008), alcohol overconsumption and/or substance abuse (Hoffart \& Jones, 2018; Niccols et al., 2010), and maternal health (Bombay et al., 2014; Niccols et al., 2010; Roy, 2014). Menzies (as cited in Hoffart \& Jones, 2018) remarked that "the prevalence of persons with mental health problems is a significant concern in the [Indigenous] population, as many individuals and communities are struggling to deal with the historical and present-day traumas associated with colonization" (p. 28). Traditional colonial and assimilation practices limit the Indigenous potential of achieving positive coping mechanisms; therefore, mental health declines. Bombay et al. (2014) theorize that youth whose parents or grandparents attended a residential school have more frequent thoughts about committing suicide and suicidal attempts (p. 324). Suicide in Indigenous communities is a current problem and directly reflects the concept of intergenerational trauma due to mental health disparities. Dated data about depression or mental health disparities in Indigenous communities do not consider the reasoning for replication among generations, such as intergenerational trauma, or the social problems that are affecting contemporary Indigenous families (Menzies, 2008, p. 42).

The ignorance of historical trauma as a result of residential schools leads to the assumption that all Indigenous individuals are more susceptible to mental health issues and other social issues in comparison to the general Canadian population (Menzies, 2008, p. 42). By ignoring the negative effect that residential schools have on the Indigenous population, mental health declines because of the replication of remaining attitudes that are not questioned. It is crucial to question the Indigenous population's mental health and well-being because it is more than a harming result of individual development, but a common issue that stems from assimilation. Some scholars believe that because there are high levels of depression within Indigenous communities, there are more significant risks for the Indigenous population to abuse alcohol or substances as a coping mechanism to deal with trauma (Hoffart \& Jones, 2018, p. 28; Niccols et al., 2010). In general, substance abuse is a common stereotype of Indigenous individuals in Canada as solely an individual issue. Many do not question the origin of Indigenous substance abuse because of the long-lasting beliefs, which are entrenched in society. Misunderstanding the implications of substance abuse as an individual concern undermines the effect of residential schools collectively as a way to cope. Specifically, there is an emphasis on the effect of substance abuse in mothers and maternal health (Niccols et al., 2010, p. 322). Chaussaneuve and Shannon et al. (as cited in Niccols et al., 2010) studied that, "[Indigenous] women report having been impacted by the historical and inter-generational effects of colonization ... and there is a link between these types of traumatic experiences and using substances as a means to cope" (p. 322). For example, Indigenous children may be born with congenital disabilities (Niccols et al., 2010, p. 323) or low birth rates (Bombay et al., 2014, p. 327), among many other outcomes that may negatively affect the rest of a child's life. Health issues that arise from maternal substance abuse are detrimental to the family structure because it replicates generationally. Believing that the Indigenous birthing process is commonly considered a 'second chance' for mothers to improve her family, maternal risk factors reflect the legacy of colonization, which may influence later generations (Roy, 2014, 
p. 221). Misunderstandings are common when addressing health disparities in the Indigenous community because of the belief that social issues derive individually where the historical implications of residential schools seem to have little to no effect on health. Therefore, it is not unexpected that health issues are still occurring in the Indigenous population as a result of ignorance of historical trauma.

\section{Intimate Partner Violence}

Violence was used in residential schools to reinforce assimilation policies utilized by residential school officials. As mentioned earlier, residential school officials had abused Indigenous students, and many exposed survivors were negatively affected; therefore, their offspring were harmfully affected as well (Bombay et al., 2015, p. 326). Hoffart and Jones (2018) describe Indigenous intimate partner violence (IPV) as a result of "a combination of a high proportion of the [Indigenous] population suffering from mental health problems, economic distress, high rates of addiction, and a history of discrimination and marginalization [contributed] to higher rates of involvement with the justice system, including high rates of family violence" (p. 29). IPV is defined by Gosselin (cited in Hoffart \& Jones, 2018) as "any form of physical, sexual, emotional, spiritual, and/or financial abuse exerted over the other to demonstrate power, control, and dominance" (p. 29). It is important to note that social stigma may be attached to a victim of IPV; therefore, Indigenous individuals may not report abuse (Hoffart \& Jones, 2018, p. 29). Violence in homes of Indigenous communities is considered healthy because children observed violence between their parents (Hoffart \& Jones, 2018, p. 40). Therefore, the cycle of violence is hard to break because of the exposure to violence in Indigenous homes, which is passed on to further generations (Hoffart \& Jones, 2018, p. 40). Using violence as a way to cope for Indigenous individuals is a common practice that stems directly from the colonial implications of residential schools and indirectly from social issues like economic disparities, mental health, substance abuse. Therefore, the social problems discussed in this paper are dependent on one another and are influenced by the Indigenous attendance of residential schools in Canada, affecting the family structure.

\section{Parental Issues and Family Struggles For Later Generations of Indigenous Canadians}

Dysfunction in the family structure is evident as a result of residential schools, intergenerational trauma, and social disparities that define the Indigenous community in Canada. As discussed earlier, the way that residential schools attempted to assimilate Indigenous Canadians by keeping them out of their homes for extended periods led to a deteriorating culture and identity, resulting in a lack of parental knowledge for survivors and their families (Menzies, 2008, 42). Because survivors of residential schools lost their self-esteem and cultural identity as children, as parents, they were "left unsure of generational boundaries, behaviour expectations, and limits" (Morrissette, 1994, p. 386). Additionally, the characterized and abusive ways residential school officials treated Indigenous children may have led to the adoption of dysfunctional relationships, 
lacking traditional role modelling (Morrissette, 1994, p. 384; Bombay et al., 2014, p. 325). The previous discussion of social problems specifically socioeconomic well-being, education, health inequalities, substance abuse, and intimate partner violence indirectly restrict Indigenous children of survivors and further generations because there are limiting numbers of resources and opportunities in these communities (Bombay et al., 2014, p. 326).

Further, Indigenous parents who survived residential schools often treated their children with neglect and abuse as a way to cope with their upbringings in residential schools. Many children living with a survivor of residential schools are apprehended from their homes by child welfare workers due to the treatment they receive at home (Morrissette, 1994, p. 385). Children were then placed in foster care or in environments that do not support the Indigenous way of life (Morrissette, 1994, p. 385). Therefore, families were disjointed, similarly to the effect of residential schools (Morrissette, 1994, p. 385). The way that most Western mainstream social institutions handle Indigenous issues are restricting because they do not adequately understand that historical implications significantly reproduce negative parenting structures. Individual actions often characterize the dysfunctional issues of Indigenous families, but it is essential to understand that history affects the Indigenous population in Canada in order to commence the healing of struggling generations.

\section{Taking Steps Toward Indigenous Healing and Solving Parental Issues}

Many suggested theories are attempting to overcome the parenting issues that characterize the Indigenous community in Canada. The negative impacts that residential schools have on survivors, families, and communities are incredibly vital to understand healing methods. For example, many Indigenous survivors who lost their sense of language in residential schools secretly learned and spoke their language in a rebellious act as part of their healing process (Bombay et al., 2014, p. 328). Additionally, Indigenous mothers believe that pregnancy is a step toward healing, "reflecting on the effects that colonization and assimilation have on the family structure" (Roy, 2014, p. 221). These women want a better life for their children because they have lived the harsh reality of family dysfunction due to the detrimental effects of residential schools on the family (Roy, 2014, p. 221). Although it is evident that residential schools negatively affect the Indigenous family structure, social problems are often primarily considered the origin of family dysfunction for generations of Indigenous parents. It is essential to understand social issues as a result of the residential school system because there are many underlying and often ignored determinants of Indigenous well-being, consequently affecting the family. In terms of formal healing processes, research suggests that institutions working with indigenous clients could "include training modules focusing on the history of colonization, the history of residential schools, and the ill effects these institutions created" (Hoffart \& Jones, 2018, p. 40). By acknowledging the effects of colonization and residential schools on the Indigenous family structure, it is no longer assumed that continual family dysfunction stems from social issues, but rather from both social issues and historical implications of colonization.

Additionally, the traditional use of Indigenous healing practices may spark healing for the family. For example, the medicine wheel, sweat lodges, and other ceremonies may initiate healing in the Indigenous community (Niccols et al., 2010, p. 327). Importantly, the medicine wheel 
approaches healing holistically to restore the balance between the individual, family, community, and nation (Menzies, 2008, p. 46). When there is an imbalance between the four realms of the medicine wheel, dysfunction may occur, representing issues that often characterize Indigenous intergenerational trauma in all aspects of life (Menzies, 2008, p. 46). Therefore, understanding and utilizing Indigenous healing methods are beneficial for the Indigenous family structure and those working with Indigenous families to encourage holistic healing that is not focussing on colonization effects.

\section{Conclusion}

The historical implications of residential schools in Canada negatively affect many generations of the Indigenous population and the family structure. Understanding that residential schools serve a purpose to assimilate the Indigenous population abolishes acceptance of traditional Indigenous language and culture. The loss of self-identity and the failure to form meaningful and intimate relationships significantly affects many generations of the Indigenous family. Forming harmful coping mechanisms as a result of the residential school environment is detrimental to the Indigenous family structure because substance abuse and intimate partner violence reflect healthy parenting of the past. Although current Indigenous social issues may act as the determinant of family dysfunction, the past should act as an associated factor in producing notions of intergenerational trauma in the Indigenous family unit. We cannot forget the past. In order to move forward, we must understand and address the role of history in destructively affecting the family structure of the Indigenous population in Canada. Undertaking action to reduce adverse effects on further generations is an enormous goal but must transpire and reflect Indigenous healing models in order to initiate restore previous conceptions of the Indigenous family. 


\section{References}

Bombay, A., Matheson, K., \& Anisman H. (2014). The intergenerational effects of Indian Residential Schools: Implications for the concept of historical trauma. Transcultural Psychiatry, 51(3), 320-338. doi:10.1177/1363461513503380

Hoffart, R., \& Jones, N. A. (2018). Intimate Partner Violence and Intergenerational Trauma Among Indigenous Women. International Criminal Justice Review, 28(1), 25-44. doi:10.1177/1057567717719966

McIvor, O., Napoleon, A., \& Dickie, K. (2009). Language and Culture as Protective Factors for At-Risk Communities. Journal of Aboriginal Health, 5(1), 6-25. doi:10.18357/ijih51200912327

Menzies, P. (2008). Developing an Aboriginal Healing Model for Intergenerational Trauma. International Journal of Health Promotion and Education, 46(2), 41-48. doi: 10.1080/14635240.2008.10708128

Mitchell, T., \& Maracle, D. (2005). Healing the Generations: Post-Traumatic Stress and the Health Status of Aboriginal Populations in Canada. Journal of Aboriginal Health, 2(1), 14-23. doi:10.3138/ijih.v2i1.28940

Morrissette, P. (1994). The Holocaust of First Nation People: Residual Effects on Parenting and Treatment Implications. Contemporary Family Therapy, 15(5), 381-392. Retrieved from https://link.springer.com/article/10.1007/BF02197900

Niccols, A., Dell, C.A., \& Clarke, S. (2010). Treatment Issues for Aboriginal Mothers with Substance Use Problems and Their Children. Int J Mental Health Addiction, 8(1), 320-335. doi:10.1007/s11469-009-9255-8

Quinn, A. (2007). Reflections on Intergenerational Trauma: Healing as a Critical Intervention. First Peoples Child \& Family Review, 3(4), 72-82. Retreived from https://library.macewan.ca/full-record/sih/28345894.

Roy, A. (2014). Intergenerational Trauma and Aboriginal Women: Implications for Mental Health During Pregnancy. First People Child \& Family Review, 9(1), 7-21. Retrieved from https://journals.sfu.ca/fpcfr/index.php/FPCFR/article/view/189 